\title{
Evaluation of a Once-Daily Vancomycin Regimen in an Outpatient Leukemia/Bone Marrow Transplant Clinic (OD-VANCO Study)
}

\author{
Cindy Luo, Trana Hussaini, Katie Lacaria, Janice Yeung, Tim T Y Lau, and Raewyn C Broady
}

\begin{abstract}
Background: The Leukemia/Bone Marrow Transplant Program of British Columbia manages patients with high-risk febrile neutropenia and those with non-neutropenic immunocompromised states in an outpatient clinic setting. Because the program treats outpatients only, once-daily administration of IV antibiotics is desirable. A high-dose, once-daily vancomycin nomogram was developed and implemented as part of the antibiotic treatment regimen.
\end{abstract}

Objective: To determine if therapeutic vancomycin trough levels could be achieved with a high-dose, once-daily regimen in this outpatient setting.

Methods: A prospective, single-centre, observational cohort study was conducted over a 7-month period. Outpatients in the Leukemia/Bone Marrow Transplant Program were started on IV vancomycin with the high-dose, once-daily vancomycin nomogram, and outcomes were assessed.

Results: Of 48 outpatients treated over the 7-month period, 10 (21\%) had therapeutic vancomycin trough concentrations (i.e., greater than $10 \mathrm{mg} / \mathrm{L})$. Thirty-five $(90 \%)$ of the 39 patients with suspected clinical infection experienced clinical cure, and $6(67 \%)$ of the 9 patients with documented microbiological infection experienced microbiological cure. Thirty (62\%) of the 48 patients experienced symptoms of "red man syndrome", and 7 (15\%) experienced some degree of nephrotoxicity. Two of 3 patients with laboratory-reported minimum inhibitory concentration (MIC) for identified pathogens had a calculated area under the curve to MIC ratio greater than or equal to 400 .

Conclusion: The high-dose, once-daily vancomycin nomogram was effective in attaining trough levels greater than $10 \mathrm{mg} / \mathrm{L}$ in only $21 \%$ of patients in this study. A substantial number of adverse drug reactions were observed. Given these results, high-dose, once-daily vancomycin is no longer recommended for outpatient therapy.

Keywords: once-daily vancomycin, febrile neutropenia, nomogram, therapeutic drug monitoring

\section{RÉSUMÉ}

Contexte : Le programme sur la leucémie et la greffe de moelle osseuse de la Colombie-Britannique (Leukemia/Bone Marrow Transplant Program of British Columbia) traite en consultation externe des patients avec une neutropénie fébrile à risque élevé et d'autres en états non neutropéniques d'immunovulnérabilité. Comme le programme s'adresse uniquement à des patients externes, une administration intraveineuse (IV) uniquotidienne d'antibiotiques est souhaitée. Pour cette raison, un nomogramme posologique pour la vancomycine à dose uniquotidienne élevée a été élaboré et mis en place dans le cadre du schéma d'antibiothérapie.

Objectif: Déterminer s'il est possible d'atteindre des concentrations minimales thérapeutiques de vancomycine à l'aide d'un schéma thérapeutique à dose uniquotidienne élevée dans ce service de consultation externe.

Méthodes : Une étude de cohorte prospective observationnelle a été menée dans un seul centre sur une période de sept mois. Le nomogramme posologique a servi à commencer le traitement IV par la vancomycine à dose uniquotidienne élevée de patients externes participant au programme sur la leucémie et la greffe de moelle osseuse, et les résultats ont été évalués.

Résultats : Parmi les quarante-huit patients externes traités pendant une période de sept mois, des concentrations minimales thérapeutiques de vancomycine (c.-̀̀-d. plus de $10 \mathrm{mg} / \mathrm{L}$ ) ont été atteintes chez dix (21\%) d'entre eux. Trente-cinq (90\%) des trente-neuf patients chez qui l'on soupçonnait une infection clinique ont obtenu une guérison clinique et une éradication microbiologique a été notée chez six (67\%) des neuf patients présentant une infection microbiologique attestée. Trente (62\%) des 48 patients ont présenté un syndrome de l'homme rouge et sept patients (15\%) ont manifesté un certain degré de néphrotoxicité. Deux des trois patients pour qui le laboratoire avait déterminé une concentration minimale inhibitrice (CMI) contre les agents pathogènes en cause avaient un rapport aire sous la courbe sur CMI égal ou supérieur à 400 .

Conclusion : Le nomogramme posologique pour la vancomycine à dose uniquotidienne élevée a permis d'atteindre des concentrations minimales de plus de $10 \mathrm{mg} / \mathrm{L}$ chez seulement $21 \%$ des patients de cette étude. Un nombre considérable d'effets indésirables liés au médicament a été observé. Compte tenu de ces résultats, il n'est plus recommandé de donner des doses uniquotidiennes élevées de vancomycine à titre de traitement aux patients externes.

Mots clés : administration uniquotidienne de vancomycine, neutropénie fébrile, nomogramme, suivi thérapeutique pharmacologique

[Traduction par l'éditeur] 


\section{INTRODUCTION}

Tfectious complications are important causes of morbidity and mortality in patients with hematologic malignancies. Although neutropenia remains a key risk factor for development of infection, non-neutropenic immunocompromised states pose a similar infection risk. ${ }^{1}$ Patients at highest risk for serious infections are those with profound, prolonged neutropenia $(<100$ cells $/ \mu \mathrm{L}$ for more than 7 days), such as those undergoing induction chemotherapy for acute leukemia and those undergoing allogeneic stem cell transplant, as well as non-neutropenic patients receiving intensive immunosuppressive treatment for graftversus-host disease. ${ }^{1,2}$ Early recognition of fever and the signs and symptoms of infection, followed by initiation of empiric broadspectrum antibiotics, is critical to reduce fatal outcomes. ${ }^{1,2}$

The Leukemia/Bone Marrow Transplant (L/BMT) Program of British Columbia treats patients with hematologic malignancies and those undergoing blood, marrow, and cord transplants. The program provides outpatient services $8-10 \mathrm{~h} /$ day, 7 days/week. Over the past 10 years, the L/BMT Program has expanded outpatient management of hematologic malignancies to cover both patients at low risk for serious complications and those considered to be at high risk who would traditionally have been managed as inpatients. This transition to outpatient management of higher-risk individuals has been driven by rising health care costs, increased demand for existing inpatient resources, improvements in supportive care, and improvements in quality of life for patients and their families. Ambulatory care has been well described for patients who have undergone autologous hematopoietic stem cell transplant or allogeneic non-myeloablative hematopoietic stem cell transplant, as well as patients with acute leukemia who are discharged before neutrophil recovery and patients receiving treatment for high-risk febrile neutropenia. ${ }^{3-6}$ The outpatient program provides care to both patients with high-risk febrile neutropenia and patients with non-neutropenic immunocompromised states.

At the time of the study, initial orders for empiric treatment of fever included an aminoglycoside, ceftriaxone, and vancomycin (Appendix 1, available online at www.cjhponline.ca/index.php/ cjhp/issue/view/103/showToc). The empiric use of vancomycin was supported by guidelines in place during the study period. ${ }^{7}$ Use of vancomycin was recommended for treatment of patients with febrile neutropenia who were receiving fluoroquinolone prophylaxis, as well as those undergoing intensive chemotherapy leading to substantial mucosal damage (e.g., high-dose cytarabine or high-dose melphalan). The most recent guidelines of the Infectious Diseases Society of America (IDSA) ${ }^{2}$ no longer recommend empiric vancomycin for these indications but do support the addition of vancomycin to initial therapy for severe mucositis if fluoroquinolone prophylaxis has been given and a cephalosporin is used for empiric treatment of febrile neutropenia.
Given the outpatient setting of the clinic, once-daily IV administration of antibiotics is desirable. Vancomycin exhibits "time-dependent kill", whereby the percentage of time that serum concentration is above the minimum inhibitory concentration (MIC) of the pathogen (\% T>MIC) is generally an indicator of pharmacodynamic activity. Current guidelines recommend dosing vancomycin to achieve trough levels greater than 10 $\mathrm{mg} / \mathrm{L}$, as therapeutic failure and development of resistance in susceptible organisms are of concern with subtherapeutic levels. ${ }^{8}$ However, it has recently been shown that the ratio of area under the concentration-time curve over $24 \mathrm{~h}$ to MIC $\left(\mathrm{AUC}_{24} / \mathrm{MIC}\right)$ is the pharmacodynamic parameter that best correlates with therapeutic efficacy. ${ }^{9}$ Moise-Broader and others ${ }^{9}$ reported that clinical and bacteriologic response to vancomycin therapy for lower respiratory tract infections caused by Staphylococcus aureus was optimized when the $\mathrm{AUC}_{24} / \mathrm{MIC}$ ratio was greater than or equal to 400 , but no relationship was found between vancomycin $\% \mathrm{~T}>\mathrm{MIC}$ and clinical response. In that study, all patients achieved $100 \%$ T>MIC.

By using high-dose, once-daily vancomycin, it should be possible to achieve $\mathrm{AUC}_{24} / \mathrm{MIC}$ ratios of greater than or equal to 400 , despite seemingly subtherapeutic trough levels and inadequate $\%$ T $>$ MIC. The concept of once-daily administration of vancomycin is supported by the fact that this drug appears to exhibit a short postantibiotic effect in vivo. ${ }^{10}$ In a mouse thigh model, vancomycin was effective in bacterial eradication, even when serum levels were below the pathogen's MIC. ${ }^{10}$ Although there is literature questioning the clinical relevance of the postantibiotic effect, these pharmacokinetic-pharmacodynamic characteristics suggest that vancomycin may still have some utility as a once-daily regimen, and its use has been reported by other researchers. ${ }^{11-14}$ Therefore, a high-dose, once-daily vancomycin nomogram was developed and implemented at the L/BMT outpatient clinic (Table 1).

The purpose of this study was to determine whether therapeutic vancomycin trough levels (i.e., greater than $10 \mathrm{mg} / \mathrm{L}$ ) could be achieved with a high-dose, once-daily dosing regimen in outpatients with or without neutropenia.

\section{Table 1. High-Dose, Once-Daily Vancomycin Regimen at the Leukemia/Bone Marrow Transplant Outpatient Clinic}

\begin{tabular}{lccc}
$\begin{array}{l}\text { Creatinine } \\
\text { Clearance } \\
\text { (mL/min) }\end{array}$ & $\begin{array}{c}\text { Loading Dose } \\
(\mathbf{m g} / \mathbf{k g})\end{array}$ & $\begin{array}{c}\text { Maintenance } \\
\text { Dose } \\
(\mathbf{m g} / \mathbf{k g})\end{array}$ & $\begin{array}{c}\text { Dosing } \\
\text { Interval }(\mathbf{h})\end{array}$ \\
\hline$>60$ & NA & 30 & 24 \\
$49-59$ & NA & 20 & 24 \\
$36-48$ & 20 & 15 & 24 \\
$24-35$ & 20 & 15 & 48 \\
\hline
\end{tabular}

*NA = not applicable. 


\section{METHODS}

\section{Study Design}

This prospective, observational cohort study was conducted in the L/BMT outpatient clinic at Vancouver General Hospital in Vancouver, British Columbia. The study protocol was reviewed and approved by the University of British Columbia Clinical Research Ethics Board and the Vancouver Coastal Health Research Institute. Data were collected over a 7-month period, from September 1, 2010, to March 31, 2011.

The study used a sample of convenience, consisting of consecutive L/BMT patients, with or without febrile neutropenia, who started vancomycin therapy during the study period. Patients were included in the study if they received at least 2 doses of vancomycin, according to the vancomycin nomogram (Table 1 ), and had a sample drawn for determination of trough level within $96 \mathrm{~h}$ after vancomycin initiation. Vancomycin was infused according to local hospital administration policies (whereby doses greater than $1.5 \mathrm{~g}$ are infused over $120 \mathrm{~min}$, and doses of $1.5 \mathrm{~g}$ or less are infused over $90 \mathrm{~min}$ ). Patients initiated on high-dose vancomycin therapy were identified using the Target Drug Report generated by the Pharmacy Department. For patients with repeated exposures to vancomycin, only the first treatment exposure was included in the analysis.

Empiric therapy was defined as initiation of antibiotic therapy for a documented clinical infection, such as cellulitis or infection at the catheter exit site, without positive results on microbiologic culture. Directed therapy was defined as antibiotic therapy against a pathogenic organism cultured from a sterile site, as in cases of bacteremia or urinary tract infection.

\section{End Points}

The primary end point was the proportion of patients in whom therapeutic vancomycin trough levels (i.e., greater than $10 \mathrm{mg} / \mathrm{L})$ were achieved. Secondary end points included the proportion of patients with clinical or microbiological cure, the proportion who experienced adverse events attributed to vancomycin (i.e., red man syndrome, nephrotoxicity, ototoxicity, or phlebitis), and the proportion with a therapeutic calculated $\mathrm{AUC}_{24} / \mathrm{MIC}$ ratio greater than or equal to 400 .

Clinical cure was defined as resolution of fever or clinical infection. Microbiological cure was defined as eradication of an organism cultured from an aseptic site after 7 to 14 days of antibiotic therapy. Red man syndrome was defined as the occurrence of thoracic flushing, pruritis, chest pain, muscle spasm, a drop of $10 \mathrm{~mm} \mathrm{Hg}$ or more in systolic blood pressure during vancomycin infusion, or documentation of treatment with diphenhydramine by the nurse in the medical records. ${ }^{15}$ The patient's estimated creatinine clearance $(\mathrm{CrCl})$ was calculated by the Cockcroft-Gault equation, and nephrotoxicity was categorized using the RIFLE criteria. ${ }^{16} \mathrm{AUC}_{24} / \mathrm{MIC}$ ratios were calculated using the Adelman and Schentag equation. ${ }^{9}$ This ratio is a pharmacokinetic parameter for assessment of drug efficacy, and current vancomycin guidelines advocate an $\mathrm{AUC}_{24} / \mathrm{MIC}$ ratio of greater than or equal to 400 to achieve clinical effectiveness. $^{8}$

\section{Statistical Analysis}

Patients were sequentially recruited from the L/BMT outpatient clinic over the study period. Demographic and clinical characteristics were summarized using medians or means for continuous variables and number (percent) for categorical variables. Descriptive statistics were used to summarize the primary and secondary outcomes. All statistical analyses were performed using Microsoft Excel 2008.

\section{RESULTS}

A total of 48 patients met the inclusion criteria and were enrolled during the study period. The median age of the study sample was 54.5 years, and median baseline serum creatinine was $77 \mu \mathrm{mol} / \mathrm{L}$ (Table 2). The mean vancomycin dose was $2073 \mathrm{mg}$, and the mean treatment duration was 5.1 days. The indication for vancomycin treatment was febrile neutropenia in 21 (44\%) of patients, empiric therapy in 18 (38\%), and directed therapy in $9(19 \%)$. Thirty-three $(69 \%)$ of the 48 patients were receiving one or more concurrent nephrotoxic agents, most commonly an aminoglycoside or liposomal amphotericin B.

\section{Primary End Point}

For $10(21 \%)$ of the 48 patients, a vancomycin trough level greater than $10 \mathrm{mg} / \mathrm{L}$ was achieved. Of the 10 patients with therapeutic trough levels, 8 had estimated $\mathrm{CrCl}$ greater than $60 \mathrm{~mL} / \mathrm{min}$, and $2 \mathrm{had} \mathrm{CrCl}$ between 49 and $59 \mathrm{~mL} / \mathrm{min}$. No patients with $\mathrm{CrCl} 48 \mathrm{~mL} / \mathrm{min}$ or less were identified during the study period.

\section{Secondary End Points}

For 41 (85\%) of the 48 patients, clinical or microbiological cure was achieved. Of the 39 patients with suspected clinical infections, 35 (90\%) achieved clinical cure. Nine patients had documented microbiological infections, of whom $6(67 \%)$ achieved microbiological cure. For 7 (15\%) of the 48 patients, the treatment failed, as indicated by development of gramnegative bacteremia in $2(29 \%)$ of the 7 patients and admission to hospital in $5(71 \%)$ of the 7 patients.

Thirty (62\%) of the 48 patients experienced red man syndrome, 1 patient (2\%) experienced phlebitis, and 7 (15\%) experienced nephrotoxicity. Of the 7 patients with nephrotoxicity, 6 were in the "risk" category and 1 was in the "injury" category, as defined by the RIFLE criteria. 
Table 2. Baseline Characteristics

\begin{tabular}{|c|c|c|}
\hline Characteristic & $\begin{array}{l}\text { No. ( } \\
\text { Pati } \\
(n=)\end{array}$ & $\begin{array}{l}\%) \text { of } \\
\text { ents* } \\
\text { 48) }\end{array}$ \\
\hline Age (yr) & & \\
\hline Median & 54.5 & \\
\hline $23-39$ & 8 & $(17)$ \\
\hline $40-49$ & 10 & (21) \\
\hline $50-60$ & 15 & (31) \\
\hline$>60$ & 15 & (31) \\
\hline Sex, male & 24 & (50) \\
\hline Serum creatinine $(\mu \mathrm{mol} / \mathrm{L})$, median & 77 & \\
\hline $\begin{array}{l}\text { Baseline absolute neutrophil count } \\
(109 / \mathrm{L}) \text { median }\end{array}$ & 0.295 & \\
\hline Vancomycin regimen & & \\
\hline Dose $(\mathrm{mg})$, mean \pm SD & 2073 & \pm 338 \\
\hline Duration (days), mean \pm SD & 5.1 & \pm 2.76 \\
\hline Type of cancer & & \\
\hline Acute myeloid leukemia & 20 & $(42)$ \\
\hline Acute lymphoblastic leukemia & 6 & (12) \\
\hline Multiple myeloma & 14 & (29) \\
\hline Myelodysplastic syndrome & 2 & (4) \\
\hline Lymphoma & 2 & (4) \\
\hline Chronic lymphocytic leukemia & 4 & (8) \\
\hline Chemotherapy regimen & & \\
\hline Induction & 15 & (31) \\
\hline Consolidation & 7 & (15) \\
\hline Autologous transplant & 16 & (33) \\
\hline Allogeneic, related & 2 & (4) \\
\hline Allogeneic, unrelated & 4 & (8) \\
\hline Palliative & 4 & (8) \\
\hline Indication for vancomycin & & \\
\hline Febrile neutropenia & 21 & (44) \\
\hline Directed therapy & 9 & (19) \\
\hline Empiric therapy & 18 & (38) \\
\hline Previous antimicrobial therapy & & \\
\hline $\begin{array}{l}\text { Ciprofloxacin with or without } \\
\text { amoxicillin-clavulanate }\end{array}$ & 35 & (73) \\
\hline Antiviral & 29 & (60) \\
\hline Antifungal & 35 & (73) \\
\hline Othert & 17 & (35) \\
\hline Concurrent nephrotoxic agentsł & & \\
\hline Aminoglycosides & 26 & (54) \\
\hline Amphotericin B & 4 & (8) \\
\hline Other & 16 & (33) \\
\hline
\end{tabular}

$\mathrm{SD}=$ standard deviation.

*Except where indicated otherwise.

+Clarithromycin, trimethoprim-sulfamethoxazole, metronidazole. ¥Some patients were receiving more than one concurrent nephrotoxic agent. Agents in the category "other" were tacrolimus, cyclosporine, pentamidine, angiotensin-converting enzyme inhibitor, pamidronate.

Three of the 7 patients with microbiological evidence of gram-positive organisms had laboratory-reported MICs (Staphylococcus epidermidis $\mathrm{MIC}<1 \mathrm{mg} / \mathrm{L}$ for all 3 isolates). For 2 of these 3 patients, the calculated $\mathrm{AUC}_{24} / \mathrm{MIC}$ ratio was greater than or equal to 400 . Both of these patients had therapeutic trough concentrations of vancomycin $(14.1$ and $18.1 \mathrm{mg} / \mathrm{L}$, respectively).

\section{DISCUSSION}

Since 2009, once-daily vancomycin has been a part of the empiric fever protocol in the L/BMT outpatient clinic at the Vancouver General Hospital. Although the regimen appeared to be clinically effective, it was unclear whether therapeutic vancomycin levels were being achieved in all patients. This study was undertaken to determine whether therapeutic vancomycin trough levels (i.e., greater than $10 \mathrm{mg} / \mathrm{L}$ ) could be achieved with a high-dose, once-daily vancomycin dosing regimen in an outpatient L/BMT patient population.

Several studies have evaluated once-daily vancomycin administration. Gilbert and others ${ }^{12}$ used a once-daily vancomycin dose of $30 \mathrm{mg} / \mathrm{kg}$ and tobramycin to treat febrile neutropenia in patients who had undergone autologous bone marrow transplant and found a reduction in the incidence of infections relative to historical controls. Avery and others ${ }^{13}$ compared a single daily dose of vancomycin $1.5 \mathrm{~g}$ in combination with tobramycin and oral ciprofloxacin with a standard multiple daily dose regimen. No significant differences in mortality, length of hospital stay, duration of neutropenia, or total infections were observed. However, the authors did not recommend the once-daily regime, as frequent regimen changes were made throughout the study period. Cohen and others ${ }^{14}$ conducted a prospective randomized study comparing IV vancomycin $30 \mathrm{mg} / \mathrm{kg}$ administered once daily or in 2 divided doses in hospital inpatients. No differences in clinical responses or toxic effects were found between the 2 dosing regimens. ${ }^{14}$

Although superiority with once-daily dosing was not clearly documented in these studies, no significant differences in mortality were observed. On the basis of work by Gilbert and others ${ }^{12}$ and Cohen and others, ${ }^{14}$ in addition to animal models suggesting potential concentration-dependent and postantibiotic effects, ${ }^{10}$ a high-dose, once-daily vancomycin dosing nomogram was developed and implemented at the study centre for the management of outpatients with febrile neutropenia and non-neutropenic immunocompromised states.

The primary objective of the current study was to determine whether the high-dose, once-daily vancomycin nomogram could achieve therapeutic vancomycin trough levels (i.e., greater than $10 \mathrm{mg} / \mathrm{L})$. However, therapeutic trough levels were achieved in only $21 \%$ of the outpatients included in the study. Possible explanations for the lower trough levels observed are that most of the patients were relatively young (median age 54.5 years) and most had normal renal function (median serum creatinine 77 $\mu \mathrm{mol} / \mathrm{L}$ ). In general, younger patients with normal renal function eliminate vancomycin at a higher rate, which may be reflected in the lower measured drug concentrations.

Clinical or microbiological cure was achieved in $41(85 \%)$ of the patients. Of these 41 patients, 34 (83\%) had vancomycin trough levels below $10 \mathrm{mg} / \mathrm{L}$, and $7(17 \%)$ reached vancomycin trough levels above $10 \mathrm{mg} / \mathrm{L}$. The low number of patients with 
therapeutic trough levels and the high cure rate are likely related to concurrent antibiotic use and are unlikely to be related to empiric use of vancomycin. Given that gram-positive pathogens were isolated from only 7 patients, vancomycin levels would have no anticipated predictive value for the cure rate for all other infections. Only 5 of the 48 patients were admitted to hospital during the study period, which indicates that treating high-risk patients in an outpatient setting is safe and feasible. Of the 5 patients admitted, 2 had a diagnosis of and were treated for possible invasive fungal pneumonia, 2 had culture-negative febrile neutropenia that resolved with count recovery (i.e. to 500 cells/ $\mu \mathrm{L}$ or above), and 1 had S. epidermidis septicemia.

Significant toxic effects were observed with high-dose vancomycin, including red man syndrome (in 62\% of the patients) and nephrotoxicity (in 15\%). Rates of red man syndrome as high as $47 \%$ have been reported in association with traditional dosing of vancomycin. ${ }^{15}$ The higher adverse reaction rates in this study suggest that an extended infusion time (greater than $2 \mathrm{~h}$ ) is warranted for high-dose vancomycin. Of the 7 patients who experienced a decline in renal function, all were receiving nephrotoxic agents, including aminoglycosides and liposomal amphotericin B. Notably, the 15 patients who did not receive any concomitant nephrotoxic agents had no decline in renal function.

In terms of the secondary end point, it was hypothesized that the $\mathrm{AUC}_{24} / \mathrm{MIC}$ ratio would provide additional insight into the efficacy of once-daily vancomycin. As proposed by MoiseBroader and others, ${ }^{9} \mathrm{AUC}_{24} / \mathrm{MIC}$ ratios greater than or equal to 400 reflect clinical and microbiological efficacy. As such, 3 of the available gram-positive isolates with recorded MICs were examined, with a view to determining whether $\mathrm{AUC}_{24} / \mathrm{MIC}$ ratio greater than or equal to 400 had been achieved. In 2 of these 3 patients, the calculated $\mathrm{AUC}_{24} / \mathrm{MIC}$ ratio was greater than or equal to 400. MIC for most commonly encountered grampositive bacteria typically ranges between 0.5 and $2.0 \mathrm{mg} / \mathrm{L}$. If it were assumed that all of the gram-positive bacteria encountered by the study patients had an MIC of $0.5 \mathrm{mg} / \mathrm{L}$, then the calculated $\mathrm{AUC}_{24} / \mathrm{MIC}$ would have been greater than or equal to 400 for 46 of the 48 patients. If an MIC of $1.0 \mathrm{mg} / \mathrm{L}$ were assumed, 21 of the 48 patients would have had a therapeutic $\mathrm{AUC}_{24} / \mathrm{MIC}$ ratio. But with an MIC of $1.5 \mathrm{mg} / \mathrm{L}$, only 3 of the 48 patients would have had a therapeutic ratio with the high-dose, oncedaily vancomycin regimen. However, with the small sample size and low number of laboratory-reported MICs available, conclusions could not be drawn regarding the usefulness of the calculated $\mathrm{AUC}_{24} / \mathrm{MIC}$ ratio and whether this ratio supports a once-daily vancomycin regime. In addition, it should be noted that the clinical relevance of the postantibiotic effect has recently been questioned. ${ }^{11}$ Using an in vitro model with once-daily tobramycin, den Hollander and others ${ }^{11}$ observed that the postantibiotic effect diminished rapidly, within one dosing interval. This finding has led some clinicians to question the clinical attributes of the postantibiotic effect.

At the time of the study, the L/BMT outpatient clinic used vancomycin in the empiric treatment of patients with febrile neutropenia who were receiving fluoroquinolone prophylaxis before fever onset or who were receiving intensive chemotherapy leading to significant mucosal damage. The results of this study prompted a re-evaluation of the practice of once-daily vancomycin use. Although the majority of patients experienced clinical or microbiological cure, only one-fifth of patients achieved a therapeutic vancomycin level, and about two-thirds of patients experienced an adverse drug reaction. These findings, in conjunction with low rates of methicillin-resistant $S$. aureus at the study institution (about 1.9\%), suggest that once-daily vancomycin may not be warranted as an initial regimen for all outpatients presenting with febrile neutropenia.

The most recent guidelines for febrile neutropenia recommend that vancomycin be considered as an addition to empiric treatment in patients with hemodynamic instability or evidence of severe sepsis, infection with gram-positive bacteria confirmed by blood culture results, clinically suspected serious catheterrelated infection or skin or soft-tissue infection at any site, known colonization with antibiotic-resistant organisms, or severe mucositis. ${ }^{2,7}$ On the basis of these study results, once-daily, highdose vancomycin is no longer included on the initial fever orders in the L/BMT outpatient clinic. Vancomycin is instead reserved for patients with the aforementioned IDSA-recommended indications. In these patients, vancomycin will be administered on a $\mathrm{q} 12 \mathrm{~h}$ regimen or adjusted according to the patient's renal function.

\section{Limitations}

The limitations of this study included the relatively short study period and the small sample size. This was a single-centre study involving a unique patient population, and these results may not be generalizable to other centres.

\section{CONCLUSIONS}

Once-daily IV antibiotic administration is desirable for the ambulatory treatment of febrile neutropenia or fever in highly immunocompromised patients who have undergone bone marrow transplant. However, high-dose, once-daily vancomycin was effective in attaining trough levels greater than $10 \mathrm{mg} / \mathrm{L}$ in only $21 \%$ of outpatients in the L/BMT Program of British Columbia, and a significant number of adverse drug reactions were observed. On the basis of these results, once-daily vancomycin is no longer recommended for outpatient management.

\section{References}

1. Baden LR, Bensinger W, Angarone M, Casper C, Dubberke ER, Freifeld AG, et al.; National Comprehensive Cancer Network. Prevention and treatment of cancer-related infections. I Natl Compr Canc Netw. 2012;10(11):1412-45 
2. Freifeld AG, Bow EJ, Sepkowtiz KA, Boeckh MJ, Ito JI, Mullen CA, et al. Clinical practice guideline for the use of antimicrobial agents in neutropenic patients with cancer: 2010 update by the Infectious Diseases Society of America. Clin Infect Dis. 2011;52(4):e56-93.

3. Teuffel O, Ethier MC, Alibhai MH, Beyene J, Sung L. Outpatient management of cancer patients with febrile neutropenia: a systematic review and meta-analysis. Ann Oncol. 2011;22(11):2358-65.

4. Savoie ML, Nevil TJ, Song KW, Forrest DL, Hogge DE, Nantel SH, et al. Shifting to outpatient management of acute myeloid leukemia: a prospective experience. Ann Oncol. 2006;17(5):763-8.

5. Halim TY, Song KW, Barnett MJ, Forrest DL, Hogge DE, Nantel SH, et al. Positive impact of selective outpatient management of high-risk acute myelogenous leukemia on the incidence of septicemia. Ann Oncol. 2007;18(7):1246-52.

6. Summers N, Dawe U, Stewart DA. A comparison of inpatient and outpatient ASCT. Bone Marrow Transplant. 2000;26(4):389-95.

7. Hughes WT, Armstrong D, Bodey GP, Bow EJ, Brown AE, Calandra T, et al. 2002 guidelines for the use of antimicrobial agents in neutropenic patients with cancer. Clin Infect Dis. 2002;34(6):730-51.

8. Rybak M, Lomaestro B, Rotschafer JC, Moellering R Jr, Craig W, Billeter $\mathrm{M}$, et al. Therapeutic monitoring of vancomycin in adult patients: a consensus review of the American Society of Health-System Pharmacists, the Infectious Diseases Society of America, and the Society of Infectious Diseases Pharmacists. Am J Health Syst Pharm. 2009;66(1):82-98. Erratum in: Am J Health Syst Pharm. 2009;66(10):887.

9 . Moise-Broader PA, Forrest A, Birmingham MC, Schentag JJ. Pharmacodynamics of vancomycin and other antimicrobials in patients with Staphylococcus aureus lower respiratory tract infections. Clin Pharmacokinet. 2004;43(13):925-42.

10. Vogelman B, Gudundsson S, Turnidge J, Leggett J, Craig WA. In vivo postantibiotic effect in a thigh infection in neutropenic mice. J Infect Dis. 1988;157(2):287-98.

11. den Hollander JG, Fuursted K, Verbrugh HA, Mouton JW. Duration and clinical relevance of postantibiotic effect in relation to the dosing interval. Antimicrob Agents Chemother. 1998;42(4):749-54.

12. Gilbert C, Meisenberg B, Vredenburgh J, Ross M, Hussein A, Perfect J, et al. Sequential prophylactic oral and empiric once-daily parenteral antibiotics for neutropenia and fever after high-dose chemotherapy and autologous bone marrow support. J Clin Oncol. 1994;12(5):1005-11.

13. Avery RK, Goldman MP, Pohlman B, Longworth DL, Mendez Z, Lauer MS, et al. A randomized trial of single daily dose vancomycin and tobramycin plus oral ciprofloxacin versus standard-dose vancomycin, ceftazidime, and tobramycin in febrile neutropenic recipients of autologous peripheral blood progenitor cell transplants. I Infect Dis Pharmacother. 2002;5(3):9-20.

14. Cohen E, Dadashev A, Drucker M, Samra Z, Rubinstein E, Garty M. Once-daily versus twice-daily intravenous administration of vancomycin for infections in hospitalized patients. J Antimicrob Chemother. 2002; 49(1):155-60

15. Wallace MR, Mascola JR, Oldfied EC 3rd. Red man syndrome: incidence, etiology and prophylaxis. J Infect Dis. 1991;164(6):1180-5.
16. Bellomo R, Ronco C, Kellum JA, Mehta RL, Palevsky P; Acute Dialysis Quality Initiative workgroup. Acute renal failure-definition, outcome measures, animal models, fluid therapy and information technology needs: the Second International Consensus Conference of the Acute Dialysis Quality Initiative (ADQI) group. Crit Care. 2004;8(4):R204-12.

Cindy Luo, BSC(Pharm), ACPR, is a Clinical Pharmacist at Vancouver General Hospital and a Clinical Instructor in the Faculty of Pharmaceutical Sciences, The University of British Columbia, Vancouver, British Columbia.

Trana Hussaini, BSc(Pharm), ACPR, PharmD, is a Pharmacotherapeutic Specialist, Solid Organ Transplantation, Vancouver General Hospital, and a Clinical Instructor, Faculty of Pharmaceutical Sciences, The University of British Columbia, Vancouver, British Columbia.

Katie Lacaria, BSC, BSC(Pharm), ACPR, is a Clinical Pharmacist, Leukemia/Bone Marrow Transplant Program of British Columbia, Vancouver General Hospital, and a Clinical Instructor, Faculty of Pharmaceutical Sciences, The University of British Columbia, Vancouver, British Columbia.

Janice Yeung, BSC(Pharm), ACPR, PharmD, is Coordinator, Lower Mainland Pharmacy Services Pharmacy Practice Residency Program; a Pharmacotherapeutic Specialist, Leukemia/Bone Marrow Transplant Program of British Columbia, Vancouver General Hospital; and a Clinical Assistant Professor, Faculty of Pharmaceutical Sciences, The University of British Columbia, Vancouver, British Columbia.

Tim T Y Lau, PharmD, ACPR, FCSHP, is a Pharmacotherapeutic Specialist, Infectious Diseases and Antimicrobial Stewardship, Vancouver General Hospital, and is also a Clinical Professor, Faculty of Pharmaceutical Sciences, and an Associate Member, Division of Infectious Diseases, Faculty of Medicine, The University of British Columbia, Vancouver, British Columbia.

Raewyn C Broady, MBChB, FRACP, is Director, Ambulatory Leukemia/Bone Marrow Transplant Program of British Columbia, Vancouver General Hospital, and Clinical Associate Professor, Division of Hematology, The University of British Columbia, Vancouver, British Columbia.

Competing interests: None declared.

\section{Address correspondence to:}

Cindy Luo

Pharmacy Department

Vancouver General Hospital

855 West 12th Avenue

Vancouver BC V5Z $1 \mathrm{M} 9$

e-mail: cindy.luo@vch.ca 